\title{
Diastereoselectivities in Reductions of $\alpha$-Alkoxy Ketones Are Not Always Correlated to Chelation-Induced Rate Acceleration
}

\author{
Nicole D. Bartolo ${ }^{-}$ \\ Alana L. Hornstein \\ Annie Y. Zhao \\ K. A. Woerpel* (1)
}

Department of Chemistry, New York University, 100 Washington Square East, New York, New York 10003, USA

kwoerpel@nyu.edu

Published as part of the 50 Years SYNTHESIS - Golden Anniversary Issue<smiles>COC(C(=O)c1ccccc1)C(=O)c1ccccc1</smiles>

$\stackrel{\text { reducing agent }}{\longrightarrow}$ reducing agent $=\mathrm{LiAlH}_{4} \quad \mathrm{Me} \quad 96: 4$ $=\mathrm{NaBH}_{4}$ $40: 60$<smiles>CO[C@H](O)[C@H](O)c1ccccc1</smiles><smiles>COCC(=O)c1ccccc1</smiles>

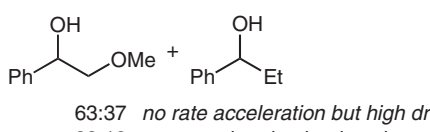

88:12 rate acceleration but low $d r$
Received: 15.10 .2018

Accepted: 18.10 .2018

Published online: 08.11 .2018

DOI: 10.1055/s-0037-1610381; Art ID: ss-2018-z0695-op

License terms: (c) $(9)$

Abstract The chelation-control model is used to predict stereochemical outcomes of many organometallic reactions. Diastereoselectivity arises due to reaction with a chelated intermediate with sterically differentiated faces. Earlier studies with dimethylmagnesium established that the chelated intermediate is a minor component of the reaction mixture, so reaction with the chelated intermediate must be faster than reaction with a non-chelated intermediate. High diastereoselectivity and chelation-induced rate acceleration are correlated with some hydride reducing agents. There are examples in which diastereoselectivity is high, but chelation-induced rate acceleration is not observed, however. In other cases, chelation-induced rate acceleration is observed, but diastereoselectivity remains low. These experiments illustrate that a revision to the chelation-control model is needed.

Key words hydride reductions, chelation control, stereoselectivity

The chelation-control model is often used by synthetic chemists to predict and explain stereoselectivity in the reductions of $\alpha$-alkoxy carbonyl compounds. Organometallic reagents form chelates to $\alpha$-alkoxy carbonyl compounds in which bond rotation is restricted, leading to steric differentiation between diastereotopic faces of the carbonyl group. $^{1-3}$ The chelation-control model assumes that the chelated intermediate is the most reactive species in solution. ${ }^{1}$ NMR spectroscopic studies established that the chelated intermediate is a minor component of the reaction mixture, so, for the reaction to be diastereoselective, the nucleophile must react more rapidly with the chelated intermediate than it does with the non-chelated form. ${ }^{2,4-6}$ If the chelated intermediate were not the most reactive species, stereoselectivity would not be high because addition to unchelated forms of the carbonyl compound would be competitive with addition to the chelated form. ${ }^{2,5}$ Although this explanation has been established for additions of or- ganomagnesium reagents to ketones, ${ }^{1,2,5-8}$ the rate acceleration due to chelation has not been established for the corresponding reductions of ketones by metal hydrides.

In this paper, we demonstrate that high diastereoselectivity in reductions of $\alpha$-alkoxy ketones is not always correlated with chelation-induced rate acceleration. A variety of hydride reducing agents were assessed for the diastereoselectivity of reduction of chiral chelating ketone $\mathbf{1}$. These stereoselectivities were then compared to competition experiments that established whether rate acceleration had accompanied selectivity.

High diastereoselectivity and rate acceleration with a chelated intermediate was observed in reactions with only some hydride reducing agents. Zinc borohydride $\left[\mathrm{Zn}\left(\mathrm{BH}_{4}\right)_{2}\right]$, a reagent commonly employed in chelation-controlled reductions, ${ }^{9-11}$ exhibited high diastereoselectivity in the reduction of $\alpha$-alkoxy ketone $\mathbf{1}$ (Table 1 ). Similarly, reduction with $\mathrm{Li}\left({ }^{\mathrm{t}} \mathrm{BuO}\right)_{3} \mathrm{AlH}$ was highly selective for the diastereomer

Table 1 Highly Diastereoselective Reductions of Ketone 1 with Different Reducing Agents

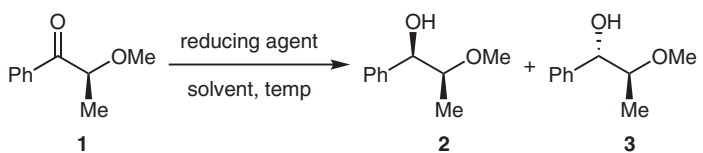

\begin{tabular}{llllll}
\hline Entry & Reducing agent & Solvent & $\begin{array}{l}\text { Temp } \\
\left({ }^{\circ} \mathrm{C}\right)\end{array}$ & $\mathbf{2} / \mathbf{3}^{\mathrm{a}}$ & $\begin{array}{l}\text { Conversion } \\
(\%)^{\mathrm{a}}\end{array}$ \\
\hline 1 & $\mathrm{Zn}\left(\mathrm{BH}_{4}\right)_{2}$ & $\mathrm{Et}_{2} \mathrm{O}$ & -78 & $>99: 1$ & 100 \\
2 & $\mathrm{Li}^{\left({ }^{\mathrm{BuOO}}\right)_{3} \mathrm{AlH}}$ & $\mathrm{Et}_{2} \mathrm{O}$ & 20 & $>99: 1$ & 100 \\
3 & $\mathrm{~N}-\mathrm{Selectride}^{\mathrm{b}}$ & $\mathrm{THF}$ & -78 & $95: 5$ & 98 \\
4 & LiAlH $_{4}$ & $\mathrm{Et}{ }_{2} \mathrm{O}$ & -78 & $96: 4$ & 100 \\
5 & Red-Al & $\mathrm{THF}$ & -78 & $92: 8$ & 97 \\
\hline
\end{tabular}

${ }^{a}$ Diastereoselectivity and conversion were determined by ${ }^{1} \mathrm{H}$ NMR spectroscopy.

${ }^{\mathrm{b}}$ Sodium tri-sec-butylborohydride.

Sodium bis(2-methoxyethoxy)aluminum hydride. 
predicted by the chelation-control model (Table 1). Rate acceleration was assessed using intermolecular competition experiments between a non-chelating ketone (5) and an $\alpha$ alkoxy ketone (4). Almost exclusive reduction of the $\alpha$ alkoxy ketone $\mathbf{4}$ was observed with these reducing agents, indicating that the rate of reaction with the chelated intermediate was accelerated when compared to the reaction of the non-chelated form (Table 2). These correlations of rate and diastereoselectivity are comparable to the rates and stereoselectivities involving additions of dialkylmagnesium and alkylmagnesium halide reagents. ${ }^{2,6-8}$

Table 2 Intermolecular Competition Experiments Demonstrate Chelation-Induced Rate Acceleration with Highly Diastereoselective Reducing Agents

\begin{tabular}{lllll}
\hline & & & 6 & \\
\hline
\end{tabular}

To rule out the possibility that the rate acceleration observed in the intermolecular competition experiment with ketones $\mathbf{4}$ and $\mathbf{5}$ could be a result of inductive effects from the $\alpha$-methoxy group in ketone $\mathbf{4}$, an intermolecular competition experiment between a ketone bearing an $\alpha$-siloxy group (8) and ketone $\mathbf{5}$ was performed. It has been documented that triisopropylsilyl (TIPS) protected alcohols generally cannot chelate due to the steric hinderance of the silyl protecting group.,12-14 As a result, $\alpha$-siloxy ketone $\mathbf{8}$ should exhibit comparable reactivity to ketone $\mathbf{5}$ if inductive effects do not contribute to the observed rate acceleration. ${ }^{2,5}$ A competition experiment between ketone $\mathbf{5}$ and $\alpha-$ siloxy ketone $\mathbf{8}$ with $\mathrm{Zn}\left(\mathrm{BH}_{4}\right)_{2}$ showed no preference for reaction with ketone $\mathbf{8}$ (Scheme 1). This observation indicates that the rate acceleration observed in Table 2 is not caused by inductive effects, but is instead due to chelation.

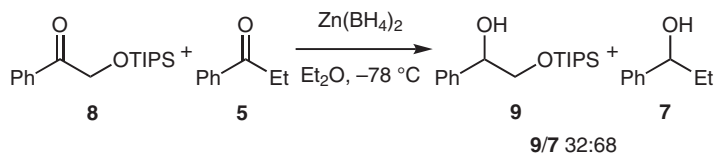

Scheme 1 Intermolecular competition experiment to assess inductive effects on rate acceleration with $\mathrm{Zn}\left(\mathrm{BH}_{4}\right)_{2}$
The divergent behavior of sodium and lithium borohydride reagents illustrates the importance of the counterion on stereoselectivity and rate. N-Selectride (sodium tri-secbutylborohydride), a borohydride reagent with a sodium counterion, diastereoselectively reduced ketone 1 to the product predicted by the chelation-control model (Table 1 ). Just as with $\mathrm{Zn}\left(\mathrm{BH}_{4}\right)_{2}$ and $\mathrm{Li}\left({ }^{\mathrm{t}} \mathrm{BuO}\right)_{3} \mathrm{AlH}, \mathrm{N}$-Selectride reacted preferentially with chelating ketone $\mathbf{4}$ in the competition experiment (Table 2), indicating that the chelated form of the ketone was likely to be the most reactive species in solution. Changing the counterion to lithium reversed these trends. L-Selectride (lithium tri-sec-butylborohydride) reacted with ketone $\mathbf{1}$ with low stereoselectivity, favoring the product predicted by the Felkin-Ahn model (Scheme 2). ${ }^{15-17}$ Furthermore, L-Selectride showed no chelation-induced rate acceleration (Scheme 3 ). The lack of enhanced reactivity of chelating ketones with L-Selectride may indicate that a chelated intermediate does not form during this reaction. Nevertheless, the two Selectride reagents exhibit the expected trends: if chelating carbonyl compounds accelerate the rate of reduction, then the reaction is highly stereoselective., ${ }^{2,5}$

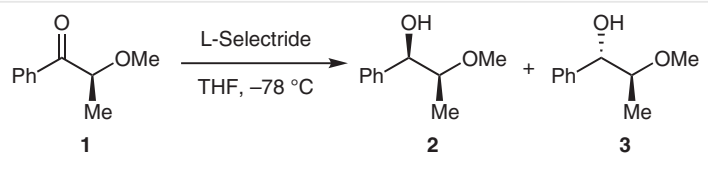

2/3 31:69

Scheme 2 Reduction of ketone 1 with L-Selectride

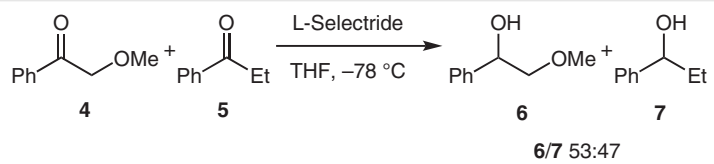

Scheme 3 Intermolecular competition experiment between a chelating and non-chelating ketone with L-Selectride

The trends observed with these metal hydride reagents, however, were not general. In a few cases, the chiral $\alpha$ alkoxy ketone $\mathbf{1}$ was reduced by aluminum hydride reagents with high diastereoselectivity but the reducing agents exhibited no chelation-induced rate acceleration. Lithium aluminum hydride $\left(\mathrm{LiAlH}_{4}\right)$, for example, reduced ketone 1 with high diastereoselectivity, but in the intermolecular competition experiment, it reacted at a similar rate with both ketones (Table 1 and Table 3). Similarly, Red-Al [sodium bis(2-methoxyethoxy)aluminum hydride] reacted with high diastereoselectivity but showed only a modest preference for reaction with the $\alpha$-alkoxy ketone. Competition experiments established that the lack of chelation-induced rate acceleration observed in reductions by these aluminum hydride reagents is not the result of inductive effects (Scheme 4). 
Table 3 Some Highly Diastereoselective Reducing Agents Show Low Preference for a Chelating Ketone in Intermolecular Competition Experiments

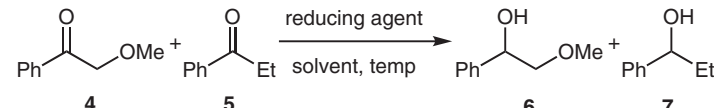

\begin{tabular}{lllll}
\hline Entry & Reducing agent & Solvent & Temp $\left({ }^{\circ} \mathrm{C}\right)$ & $\mathbf{6} / \mathbf{7}^{\mathrm{a}}$ \\
\hline 1 & $\mathrm{LiAlH}_{4}$ & $\mathrm{Et}_{2} \mathrm{O}$ & -78 & $63: 37$ \\
2 & Red-Al $^{\mathrm{b}}$ & $\mathrm{Et}_{2} \mathrm{O}$ & -78 & $77: 23$ \\
\hline
\end{tabular}

a Product ratios determined by GC analysis.

b Sodium bis(2-methoxyethoxy)aluminum hydride.

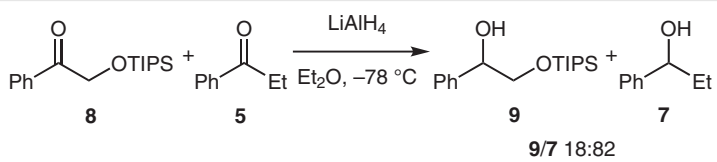

Scheme 4 Intermolecular competition experiment to assess inductive effects on rate acceleration with $\mathrm{LiAlH}_{4}$

The results with these reagents do not fit neatly into the chelation-control model. Unlike the Selectride reagents, diastereoselectivities for reductions using these aluminum hydride reagents were high with both lithium and sodium counterions. The high diastereoselectivities imply that chelated intermediates with sterically differentiated faces were formed in the course of the reaction. Because rate acceleration was not observed in this example, the reaction could be diastereoselective if the chelated intermediate were the major component of the reaction mixture. ${ }^{8}$ This explanation, however, would suggest that the same would be true of the Selectride reagents. Instead, with these reagents, chelation-controlled selectivity occurred only with the sodium counterion.

The diastereoselectivities observed with borohydride reagents are even more difficult to reconcile with the chelation-control model. For example, diastereoselectivity for reduction with sodium borohydride varied with the solvent. The reaction was moderately diastereoselective for the product predicted by the chelation-control model (2) in solvents such as methanol and dioxane (Table 4). In water and DMSO, however, the diastereoselectivity shifted to favor the product predicted by the Felkin-Ahn stereochemical model (3).

In intermolecular competition experiments to assess rate acceleration, the rate of reduction of the $\alpha$-alkoxy ketone 4 was similar in both methanol and DMSO despite large differences in the diastereoselectivities observed for these solvents (Table 5). For the reduction in methanol, this result is consistent with the chelation-control model: con-
Table 4 Reductions of Ketone 1 with Sodium Borohydride

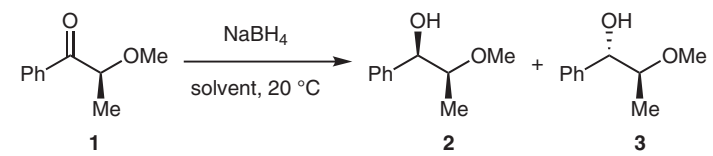

\begin{tabular}{llll}
\hline Entry & Solvent & $\mathbf{2 / 3}^{\mathrm{a}}$ & Conversion (\%) $^{\mathrm{a}}$ \\
\hline 1 & dioxane & $87: 13$ & 100 \\
2 & THF & $87: 13$ & 69 \\
3 & hexane & $85: 15$ & 100 \\
4 & $\mathrm{MeCN}$ & $85: 15$ & 100 \\
5 & $\mathrm{Et}_{2} \mathrm{O}+\mathrm{H}_{2} \mathrm{O}^{\mathrm{b}}$ & $84: 16$ & 100 \\
6 & $\mathrm{MeOH}$ & $80: 20$ & 100 \\
7 & ${ }^{\mathrm{PrOH}}$ & $80: 20$ & 100 \\
8 & $\mathrm{C}_{6} \mathrm{H}_{6}$ & $77: 23$ & 75 \\
9 & pyridine & $70: 30$ & 100 \\
10 & $\mathrm{C}_{6} \mathrm{H}_{6}+\mathrm{H}_{2} \mathrm{O}^{\mathrm{b}}$ & $53: 47$ & 98 \\
11 & DMF $_{12}$ & $48: 52$ & 100 \\
12 & $\mathrm{CH}_{2} \mathrm{Cl}_{2}$ & $46: 54$ & 89 \\
13 & $\mathrm{H}_{2} \mathrm{O}$ & $42: 58$ & 100 \\
14 & DMSO $^{2}$ & $40: 60$ & 100 \\
\hline${ }^{\mathrm{a}}$ Diastereoselectivity and conversion were determined by ${ }^{1} \mathrm{H}$ NMR spec- \\
troscopy. \\
${ }^{\mathrm{b}}$ Water $\left(2\right.$ equiv) was added per equivalent of $\mathrm{NaBH}_{4}$ to increase solubility.
\end{tabular}

sidering that the chelated intermediate was only somewhat more reactive, the reduction was only moderately stereoselective. The reaction with $\mathrm{NaBH}_{4}$ in DMSO was accelerated by the chelating group, but the reaction was not diastereoselective. Competition experiments between $\alpha$-siloxy ketone $\mathbf{8}$ and ketone $\mathbf{5}$ suggest that the rate acceleration observed in both methanol and DMSO is not the result of inductive effects (Table 6). Taken together, these results indicate that rate acceleration with a chelated intermediate does not necessarily lead to increased stereoselectivity as would be predicted by the chelation-control model.

Table 5 Intermolecular Competition Experiments To Assess ChelationInduced Rate Acceleration with $\mathrm{NaBH}_{4}$

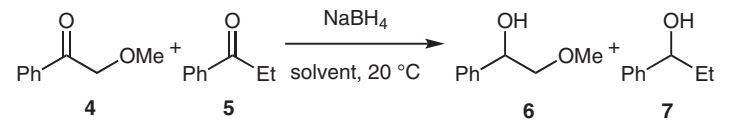

\begin{tabular}{lcc}
\hline Entry & Solvent & $\mathbf{6 / 7 ^ { a }}$ \\
\hline 1 & MeOH & $79: 21$ \\
2 & DMSO & $88: 12$ \\
\hline
\end{tabular}

a Product ratios determined by GC analysis. 
Table 6 Intermolecular Competition Experiments To Assess Inductive Effects on Rate Acceleration with $\mathrm{NaBH}_{4}$

\begin{tabular}{lll} 
& & \\
\hline Entry & Solvent & $9 / \mathbf{7}^{\text {a }}$ \\
\hline 1 & MeOH & $18: 82$ \\
2 & DMSO & $21: 79$ \\
\hline
\end{tabular}

a Product ratios determined by GC analysis.

${ }^{1} \mathrm{H}$ and ${ }^{13} \mathrm{C}$ NMR spectroscopic studies of $\alpha$-alkoxy ketone $\mathbf{4}$ in the presence of sodium borohydride failed to provide evidence for a chelated intermediate. In $\mathrm{CD}_{3} \mathrm{OD}$, the reduction proceeded too quickly for measurement by NMR spectroscopy. In DMSO- $d_{6}$, however, the reduction was slow enough to observe that there was no change in the chemical shifts of ketone $\mathbf{4}$ in the presence of sodium borohydride. Even though chelation of ketone $\mathbf{4}$ was not observed, solvation of the sodium borohydride was observed in the ${ }^{1} \mathrm{H}$ NMR spectrum. ${ }^{18}$ Experiments with another borate salt with a sodium counterion also did not support a significant amount of chelation. No change in the chemical shifts of ketone 4 was observed in the presence of $\mathrm{NaBF}_{4}$ in either $\mathrm{CD}_{3} \mathrm{OD}$ or DMSO- $d_{6}$. These experiments suggest that the chelated intermediate is a minor component of the reaction mixture in both solvents, as has been observed in NMR experiments with dimethylmagnesium. ${ }^{5}$ This conclusion does not, however, provide an explanation for the low diastereoselectivity in the reduction of ketone $\mathbf{1}$ in DMSO even though rate acceleration was observed.

No diastereoselectivity was observed in the reduction of chiral $\alpha$-alkoxy ketone 1 with lithium borohydride and potassium borohydride (Table 7). Just as with the reduction using sodium borohydride in DMSO, competition experiments indicated that chelation accelerated the reduction of $\alpha$-alkoxy ketone 4 (Table 8). ${ }^{1} \mathrm{H}$ and ${ }^{13} \mathrm{C}$ NMR spectroscopic studies of ketone $\mathbf{4}$ with lithium borohydride and potassium borohydride in $\mathrm{CD}_{3} \mathrm{OD}$ could not be employed to show evidence of a chelated intermediate, because both reactions occurred too quickly to obtain a measurement before the ketone was fully reduced. Additional experiments showed that the rate acceleration observed with both lithium borohydride and potassium borohydride is not the result of inductive effects (Table 9). Sodium cyanoborohydride, like sodium borohydride in methanol, reduced ketone $\mathbf{1}$ with moderate diastereoselectivity and showed moderate rate acceleration in the reduction of $\alpha$-alkoxy ketone 4 in the intermolecular competition experiment (Tables 7 and 8).

Diastereoselectivity in the reductions of ketone $\mathbf{1}$ with diisobutylaluminum hydride $\left({ }^{i} \mathrm{Bu}_{2} \mathrm{AlH}\right)$ were also strongly influenced by solvent. While moderate diastereoselectivity was observed for the product from chelation (2) in THF, the
Table 7 Stereoselectivity in Reductions with Other Borohydride Reducing Agents

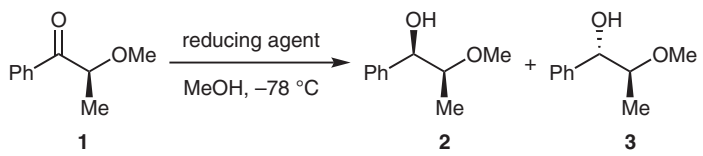

\begin{tabular}{llll}
\hline Entry & Reducing agent & $\mathbf{2 / \mathbf { 3 } ^ { \mathrm { a } }}$ & Conversion (\%) \\
\hline 1 & $\mathrm{LiBH}_{4}$ & $47: 53$ & 88 \\
2 & $\mathrm{KBH}_{4}$ & $54: 46$ & 100 \\
3 & $\mathrm{NaBH}_{3} \mathrm{CN}$ & $75: 25$ & 57 \\
\hline
\end{tabular}

${ }^{\mathrm{a}}$ Diastereoselectivity and conversion were determined by ${ }^{1} \mathrm{H}$ NMR spectroscopy.

Table 8 Intermolecular Competition Experiments To Assess ChelationInduced Rate Acceleration with Borohydride Reducing Agents

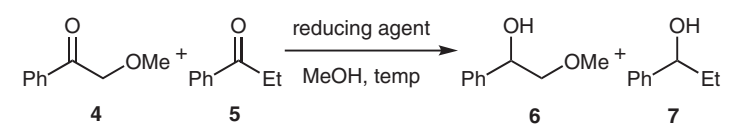

\begin{tabular}{llll}
\hline Entry & Reducing agent & Temp $\left({ }^{\circ} \mathrm{C}\right)$ & $\mathbf{6} / \mathbf{7}^{\mathrm{a}}$ \\
\hline 1 & $\mathrm{LiBH}_{4}$ & -78 & $79: 21$ \\
2 & $\mathrm{KBH}_{4}$ & -78 & $85: 15$ \\
3 & $\mathrm{NaBH}_{3} \mathrm{CN}$ & 20 & $67: 33$ \\
\hline
\end{tabular}

a Product ratios determined by GC analysis.

Table 9 Intermolecular Competition Experiments To Assess Inductive Effects on Rate Acceleration with Borohydride Reducing Agents

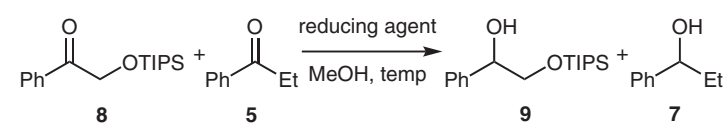

\begin{tabular}{llll}
\hline Entry & Reducing agent & Temp $\left({ }^{\circ} \mathrm{C}\right)$ & $\mathbf{9} / \mathbf{7}^{\text {a }}$ \\
\hline 1 & $\mathrm{LiBH}_{4}$ & -78 & $8: 92$ \\
2 & $\mathrm{KBH}_{4}$ & 20 & $37: 63$ \\
\hline
\end{tabular}

a Product ratios determined by GC analysis.

reductions were unselective in dichloromethane, diethyl ether, and benzene (Table 10). This trend is opposite to the trend observed for additions of allylmagnesium reagents to ketones, where chelation-controlled addition was more favored in solvents such as dichloromethane compared to THF and diethyl ether. ${ }^{8}$ In hexane, the product derived from the Felkin-Ahn stereochemical model (3) was preferred. The intermolecular competition experiment between $\alpha$ alkoxy ketone $\mathbf{4}$ and ketone $\mathbf{5}$ in THF showed no preference for reduction of one ketone over the other (Table 11). When the competition experiment was performed in hexane, the reaction favored reduction of the non-chelating ketone $\mathbf{5}$. 
This outcome was expected because ${ }^{i} \mathrm{Bu}_{2} \mathrm{AlH}$ cannot chelate, ${ }^{5,12,19}$ but evidently there is no acceleration by inductive effects exerted by the OMe group. ${ }^{20}$ In addition, competition experiments to assess inductive effects directly showed no preference for the reduction of $\alpha$-siloxy ketone $\mathbf{8}$ in either THF or hexane (Table 12).

Table 10 Reductions of Ketone 1 with ${ }^{i} \mathrm{Bu}_{2} \mathrm{AlH}$

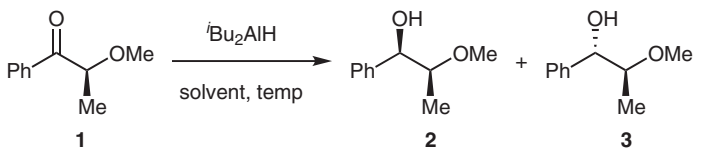

\begin{tabular}{lllll}
\hline Entry & Solvent & Temp $\left({ }^{\circ} \mathrm{C}\right)$ & $\mathbf{2} / \mathbf{3}^{\mathrm{a}}$ & ${\text { Conversion }(\%)^{\mathrm{a}}}^{\mathrm{a}}$ \\
\hline 1 & THF & -78 & $76: 24$ & 100 \\
2 & $\mathrm{CH}_{2} \mathrm{Cl}_{2}$ & -78 & $58: 42$ & 100 \\
3 & $\mathrm{Et}_{2} \mathrm{O}$ & -78 & $53: 47$ & 100 \\
4 & $\mathrm{C}_{6} \mathrm{H}_{6}$ & 20 & $45: 55$ & 100 \\
5 & hexane & -78 & $28: 72$ & 100 \\
\hline
\end{tabular}

${ }^{a}$ Diastereoselectivity and conversion were determined by ${ }^{1} \mathrm{H}$ NMR spectroscopy.

Table 11 Intermolecular Competition Experiments To Assess Chelation-Induced Rate Acceleration with ${ }^{\mathrm{B}} \mathrm{Bu}_{2} \mathrm{AlH}$

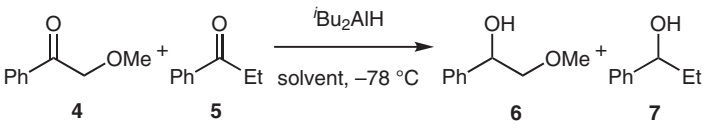

\begin{tabular}{lll}
\hline Entry & Solvent & $\mathbf{6} / \mathbf{7}^{\mathrm{a}}$ \\
\hline 1 & THF & $46: 54$ \\
2 & hexane & $19: 81$ \\
\hline a Product ratios determined by CC andysis &
\end{tabular}

a Product ratios determined by GC analysis.

Table 12 Intermolecular Competition Experiments To Assess Inductive Effects on Rate Acceleration with ${ }^{\mathrm{B}} \mathrm{Bu} \mathrm{AlH}_{2} \mathrm{AlH}$

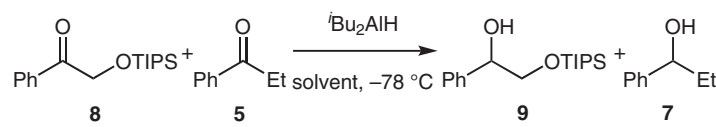

\begin{tabular}{lll}
\hline Entry & Solvent & $\mathbf{9 / \mathbf { 7 } ^ { \mathrm { a } }}$ \\
\hline 1 & THF & $<1: 99$ \\
2 & hexane & $3: 97$ \\
\hline
\end{tabular}

a Product ratios determined by GC analysis.

Reduction of $\alpha$-alkoxy ketone 1 with triisobutylaluminum $^{21}\left({ }^{i} \mathrm{Bu}_{3} \mathrm{Al}\right)$ in diethyl ether gave the Felkin-Anh product (3, Scheme 5). An intermolecular competition experiment showed no preference for reaction with the $\alpha$-alkoxy ketone $\mathbf{4}$ over non-chelating ketone $\mathbf{5}$, as would be expected based upon the diastereoselectivity (Scheme 6).

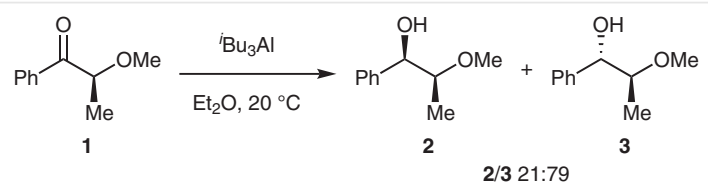

Scheme 5 Reduction of ketone 1 with ${ }^{~} \mathrm{Bu}_{3} \mathrm{Al}$

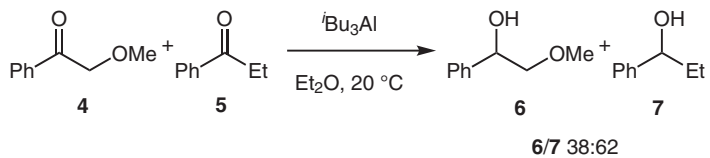

Scheme 6 Intermolecular competition experiment between a chelating and non-chelating ketone with ${ }^{i} \mathrm{Bu}_{3} \mathrm{Al}$

Taken together, the results described above are difficult as a group to accommodate with the chelation-control model. ${ }^{1,2,5,8}$ That model involves a Curtin-Hammett kinetic scenario $^{2,22}$ in which the chelated form is more reactive than other species in solution, and addition to that intermediate is diastereoselective. These results with reductions of ketones show that, although reactivity and selectivity are correlated in some cases, in many other cases they are not. Figure 1 illustrates the lack of correlation between diastereoselectivity and chelation-induced rate acceleration. This plot of diastereoselectivity vs chelation-induced rate acceleration using the data from the above tables does not show a clear trend across all reactions. Data points on or near the trendline $(\mathrm{y}=\mathrm{x})$ would indicate a correlation between diastereoselectivity and chelation-induced rate acceleration, as predicted by the chelation-control model. Evidently, in some cases, such as the reduction using $\mathrm{LiAlH}_{4}$, the two faces are sufficiently differentiated without any evidence that the chelate is either favored or more reactive. Conversely, reaction through a chelate, as indicated by rate acceleration, is not a sufficient condition to observe diastereoselectivity (i.e., reduction with $\mathrm{NaBH}_{4}$ in DMSO). All that is required to observe diastereoselectivity is that addition to the two diastereotopic faces of the ketone occur at different rates. These results illustrate that although we can ascribe one product as formed by chelation-control and another as formed through a Felkin-Anh transition state, many modes of addition lead to product, and it is possible that the products are formed from multiple pathways with different origins of stereoselectivity. ${ }^{23,24}$

In conclusion, these experiments indicate that a revision to the chelation-control model is needed. The model does not include cases where diastereoselectivity is not correlated to rate acceleration with a chelated intermediate. It also does not include cases where no diastereoselectivity is observed even though there is rate acceleration with a chelated intermediate as observed in competition experiments. 


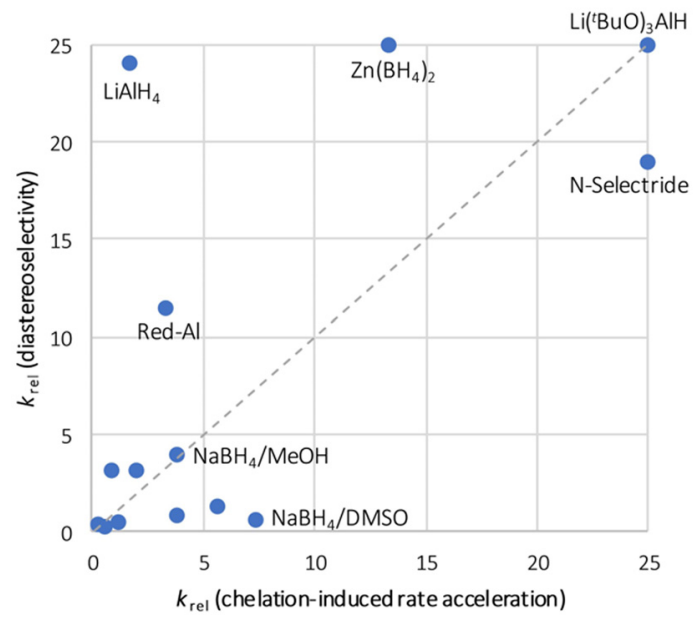

Figure 1 Diastereoselectivity in the reductions of chiral $\alpha$-alkoxy ketone $\mathbf{1}$ is not necessarily correlated with chelation-induced rate acceleration

${ }^{1} \mathrm{H}$ NMR spectra were obtained at room temperature using Bruker AVIII-400 (400 MHz and $100 \mathrm{MHz}$, respectively), AVIIIHD-400 (400 $\mathrm{MHz}$ and $100 \mathrm{MHz}$, respectively), AV-500 (500 MHz and $125 \mathrm{MHz}$, respectively), and AV-600 (600 MHz and $150 \mathrm{MHz}$, respectively) spectrometers; spectroscopic data are reported as follows: chemical shifts in ppm on the $\delta$ scale, referenced to residual solvent ( ${ }^{1} \mathrm{H}$ NMR: $\mathrm{CDCl}_{3} \delta$ 7.26; ${ }^{13} \mathrm{C}$ NMR: $\mathrm{CDCl}_{3} \delta 77.2$ ), multiplicity (standard abbreviations), coupling constant $(\mathrm{s})(\mathrm{Hz})$, and integration. Ratios of products were obtained from one-pulse ${ }^{1} \mathrm{H}$ NMR integrations using diagnostic peaks in unpurified reaction mixtures. One-pulse ${ }^{1} \mathrm{H}$ spectra were taken with a relaxation delay of $30 \mathrm{~s}$ when determining product ratios. Multiplicities of carbon peaks were determined using HSQC experiments. Product distributions of competition experiments were determined by gas chromatography, using an Agilent 6850 Series gas chromatograph with the carrier gas (helium) set to 15 psi and equipped with a capillary column (14\% cyanopropylphenyl, $86 \%$ methylpolysiloxane, $30 \mathrm{~m} \times 0.321 \mathrm{~mm} \times 0.25 \mu \mathrm{m})$. High-resolution mass spectra were acquired on an Agilent 6224 Accurate-Mass time-of-flight spectrometer with an atmospheric pressure chemical ionization (APCI) source. Infrared (IR) spectra were recorded using a Thermo Nicolet AVATAR Fourier Transform IR spectrometer using attenuated total reflectance (ATR). Liquid chromatography was performed using forced flow (flash chromatography) of the indicated solvent system on silica gel 60 (230-400 mesh). Tetrahydrofuran, diethyl ether, dichloromethane, benzene, hexane, acetonitrile, dimethylformamide, and methanol were dried and degassed using a solvent purification system before use. All anhydrous reactions were run under a nitrogen atmosphere in glassware that had been flame-dried under vacuum. Ketone $\mathbf{1},{ }^{25} \mathrm{ke}-$ tone $4,{ }^{8}$ ketone $8,{ }^{26}$ and zinc borohydride ${ }^{27}$ were prepared by known methods. Unless otherwise noted, all reagents and substrates were commercially available. The concentrations of commercially available reagents were assumed to be near the concentrations reported by the suppliers.

\section{Reduction of Ketone 1; Representative Procedure}

To a cooled $\left(-78{ }^{\circ} \mathrm{C}\right)$ solution of $\mathrm{LiAlH}_{4}(0.064 \mathrm{~g}, 1.7 \mathrm{mmol})$ in $\mathrm{Et}_{2} \mathrm{O}(3$ $\mathrm{mL}$ ) was added a solution of ketone $\mathbf{1}(0.082 \mathrm{~g}, 0.50 \mathrm{mmol})$ in $\mathrm{Et}_{2} \mathrm{O}(3$ $\mathrm{mL}$ ) dropwise. After $4 \mathrm{~h}, \mathrm{MeOH}(2 \mathrm{~mL})$ was added. The solution was warmed to room temperature and brine $(10 \mathrm{~mL})$ was added. The mixture was extracted with $\mathrm{CH}_{2} \mathrm{Cl}_{2}(3 \times 10 \mathrm{~mL})$ and the combined organic layers were dried over $\mathrm{Na}_{2} \mathrm{SO}_{4} .{ }^{1} \mathrm{H}$ NMR spectroscopic analysis of the unpurified reaction mixture revealed a 96:4 mixture of diastereomers (2/3). Purification by flash chromatography (EtOAc-hexanes, 15:85) afforded a mixture of alcohols $\mathbf{2}$ and $\mathbf{3}$ as a colorless oil, with a diastereomeric ratio of 94:6; yield: $0.071 \mathrm{~g}(85 \%)$. The spectroscopic data are consistent with literature data. ${ }^{28,29}$

IR (neat): 3458, 2980, 1451, 1026, $824 \mathrm{~cm}^{-1}$.

${ }^{1} \mathrm{H} \mathrm{NMR}\left(400 \mathrm{MHz}, \mathrm{CDCl}_{3}\right): \delta=7.35-7.28(\mathrm{~m}, 5 \mathrm{H}), 4.91(\mathrm{~m}, 1 \mathrm{H}), 3.57-$ $3.51(\mathrm{~m}, 1 \mathrm{H}), 3.42(\mathrm{~s}, 3 \mathrm{H}), 2.55(\mathrm{br} \mathrm{s}, 1 \mathrm{H}), 0.98(\mathrm{~d}, J=6.3 \mathrm{~Hz}, 3 \mathrm{H})$.

${ }^{13} \mathrm{C}$ NMR (100 MHz, $\left.\mathrm{CDCl}_{3}\right): \delta=140.7(\mathrm{C}), 128.4(\mathrm{CH}), 127.5(\mathrm{CH})$, $126.5(\mathrm{CH}), 81.0(\mathrm{CH}), 74.7(\mathrm{CH}), 56.9\left(\mathrm{CH}_{3}\right), 12.8\left(\mathrm{CH}_{3}\right)$.

HRMS (APCI): $m / z\left[(\mathrm{M}+\mathrm{H})-\mathrm{H}_{2} \mathrm{O}\right]^{+}$calcd for $\mathrm{C}_{10} \mathrm{H}_{13} \mathrm{O}: 149.0961$; found: 149.0957 .

\section{Competition Experiment between Ketone 4 and Ketone 5; Repre- sentative Procedure}

To a cooled $\left(-78{ }^{\circ} \mathrm{C}\right)$ solution of ketone $\mathbf{4}(0.045 \mathrm{~g}, 0.30 \mathrm{mmol})$ and ketone $5(0.040 \mathrm{~mL}, 0.30 \mathrm{mmol})$ in $\mathrm{Et}_{2} \mathrm{O}(3 \mathrm{~mL})$ was added $\mathrm{Zn}\left(\mathrm{BH}_{4}\right)_{2}$ $\left(0.500 \mathrm{~mL}, 0.15 \mathrm{M}\right.$ solution in $\left.\mathrm{Et}_{2} \mathrm{O}, 0.075 \mathrm{mmol}\right)$ dropwise. After stirring for $12 \mathrm{~h}, \mathrm{MeOH}(1 \mathrm{~mL})$ was added, and the reaction mixture was warmed to room temperature over $15 \mathrm{~min}$. An aliquot of the reaction mixture $(1 \mathrm{~mL})$ was filtered through a plug of silica gel and analyzed by GC ( start temperature $=80^{\circ} \mathrm{C}, \mathrm{ramp}=10^{\circ} \mathrm{C} / \mathrm{min}$, final temperature $=170{ }^{\circ} \mathrm{C}$ ) to show a $93: 7$ mixture of products $(6 / 7)$, using the retention times of authentic samples prepared as a reference.

\section{Competition Experiment between Ketone 8 and Ketone 5; Repre- sentative Procedure}

To a cooled $\left(-78{ }^{\circ} \mathrm{C}\right)$ solution of ketone $8(0.088 \mathrm{~g}, 0.30 \mathrm{mmol})$ and ketone $5(0.040 \mathrm{~mL}, 0.30 \mathrm{mmol})$ in $\mathrm{Et}_{2} \mathrm{O}(3 \mathrm{~mL})$ was added $\mathrm{Zn}\left(\mathrm{BH}_{4}\right)_{2}$ $\left(0.500 \mathrm{~mL}, 0.15 \mathrm{M}\right.$ solution in $\left.\mathrm{Et}_{2} \mathrm{O}, 0.075 \mathrm{mmol}\right)$ dropwise. After stirring for $12 \mathrm{~h}, \mathrm{MeOH}(1 \mathrm{~mL})$ was added, and the reaction mixture was warmed to room temperature over $15 \mathrm{~min}$. An aliquot of the reaction mixture $(1 \mathrm{~mL})$ was filtered through a plug of silica gel and analyzed by GC (start temperature $=150{ }^{\circ} \mathrm{C}$, ramp $=50^{\circ} \mathrm{C} / \mathrm{min}$, final temperature $=250{ }^{\circ} \mathrm{C}$ ) to show a $52: 48$ mixture of products $(\mathbf{9} / 7)$, using the retention times of authentic samples prepared as a reference. This ratio was corrected to 32:68 using a GC to ${ }^{1} \mathrm{H}$ NMR calibration curve (second-order polynomial regression, $\mathrm{y}=-0.0067 \mathrm{x}^{2}+1.6296 \mathrm{x}+$ $2.7501, R^{2}=0.9992$ ) derived from seven mixtures of pure alcohols 9 and 7; the variable $\mathrm{y}=$ the percentage of 9 by GC, and $\mathrm{x}=$ the percentage of 9 by ${ }^{1} \mathrm{H}$ NMR spectroscopy.

\section{Funding Information}

Acknowledgment is made to the Donors of the American Chemical Society Petroleum Research Fund for support of this research (57206ND1). The Shared Instrumentation Facility in the Department of Chemistry was constructed through the support of the National Center for Research Resources, National Institutes of Health, under Research Facilities Improvement Award Number C06 RR-16572-01. The cryogenic probe for the $600 \mathrm{MHz}$ NMR was acquired through the support of the National Institute of Health S10 grant under Award Number OD016343. 


\section{Acknowledgment}

We thank Dr. Chin Lin (NYU) for assistance with NMR spectroscopy and mass spectrometry.

\section{Supporting Information}

Supporting information for this article is available online at https://doi.org/10.1055/s-0037-1610381.

\section{References}

(1) Chen, X.; Hortelano, E. R.; Eliel, E. L.; Frye, S. V. J. Am. Chem. Soc. 1990, $112,6130$.

(2) Chen, X.; Hortelano, E. R.; Eliel, E. L.; Frye, S. V. J. Am. Chem. Soc. $1992,114,1778$.

(3) Eliel, E. L.; Frye, S. V.; Hortelano, E. R.; Chen, X.; Bai, X. Pure Appl. Chem. 1991, 63, 1591.

(4) Mori, S.; Nakamura, M.; Nakamura, E.; Koga, N.; Morokuma, K. J. Am. Chem. Soc. 1995, 117, 5055.

(5) Frye, S. V.; Eliel, E. L.; Cloux, R. J. Am. Chem. Soc. 1987, 109, 1862.

(6) Reetz, M. T. Acc. Chem. Res. 1993, 26, 462.

(7) Reetz, M. T.; Raguse, B.; Marth, C. F.; Hügel, H. M.; Bach, T.; Fox, D. N. A. Tetrahedron 1992, 48, 5731 .

(8) Read, J. A.; Yang, Y.; Woerpel, K. A. Org. Lett. 2017, 19, 3346.
(9) Takahashi, T.; Miyazawa, M.; Tsuji, J. Tetrahedron Lett. 1985, 26, 5139.

(10) Iida, H.; Yamazaki, N.; Kibayashi, C. J. Org. Chem. 1986, 51, 3769.

(11) Nakata, T.; Tanaka, T.; Oishi, T. Tetrahedron Lett. 1983, 24, 2653.

(12) Frye, S. V.; Eliel, E. L. Tetrahedron Lett. 1986, 27, 3223.

(13) Corey, E. J.; Cho, H.; Rücker, C.; Hua, D. H. Tetrahedron Lett. 1981, $22,3455$.

(14) Stanton, G. R.; Johnson, C. N.; Walsh, P. J. J. Am. Chem. Soc. 2010, $132,4399$.

(15) Anh, N. T.; Eisenstein, O.; Lefour, J. M.; Trân Huu Dâu, M.-E. J. Am. Chem. Soc. 1973, 95, 6146.

(16) Chérest, M.; Felkin, H. Tetrahedron Lett. 1968, 2205.

(17) Chérest, M.; Felkin, H.; Prudent, N. Tetrahedron Lett. 1968, 2199.

(18) Hepp, A.; Labbow, R.; Reiß, F.; Schulz, A.; Villinger, A. Eur. J. Inorg. Chem. 2018, 2905.

(19) Ko, K.-Y.; Frazee, W. J.; Eliel, E. L. Tetrahedron 1984, 40, 1333.

(20) Das, G.; Thornton, E. R. J. Am. Chem. Soc. 1990, 112, 5360.

(21) Winterfeldt, E. Synthesis 1975, 617.

(22) Seeman, J. I. Chem. Rev. 1983, 83, 83.

(23) Tietze, L. F.; Kinzel, T.; Schmatz, S. Chem. Eur. J. 2009, 15, 1706.

(24) Wigfield, D. C. Tetrahedron 1979, 35, 449.

(25) Bartolo, N. D.; Woerpel, K. A. J. Org. Chem. 2018, 83, 10197.

(26) Cho, B. T.; Chun, Y. S. J. Org. Chem. 1998, 63, 5280.

(27) Paterson, I.; Fink, S. J.; Lee, L. Y. W.; Atkinson, S. J.; Blakey, S. B. Org. Lett. 2013, 15, 3118.

(28) Nadkarni, D.; Hallissey, J.; Mojica, C. J. Org. Chem. 2003, 68, 594.

(29) Shibata, I.; Yoshida, T.; Kawakami, T.; Baba, A.; Matsuda, H. J. Org. Chem. 1992, 57, 4049 . 